\title{
Research on Teaching Reform of College Statistics Course in the Age of Big Data
}

\author{
WU Di \\ Baicheng Normal University, Baicheng, 137000,China \\ email: 343401333@163.com
}

Keywords: the Age of Big Data, Statistics Course, Teaching Reform

\begin{abstract}
With the rise of the Internet, people's way of life has changed dramatically. We can read news or interesting things thousands of miles away on our mobile phones without leaving home, and we can browse the information we want on our computers by moving our fingers. For enterprises, the use of data to understand customer demand and consumption habits, and can easily enough to achieve market positioning and market segmentation, so as to achieve the purpose of data management enterprise structure, enterprise production. For government organizations, big data can directly reflect the needs of the people, thus improving the governance of government departments, service concepts and policy changes, which is conducive to the unified management of the country. In March 2015, relevant leaders at the two sessions also particularly stressed the importance of big data, so that the common people understand big data and feel the change in life made by big data. To sum up, big data has been widely used in the life of the masses, in the management of enterprises, and in the governance of the country. In such an age background, the talent required by the big data technology has become the object of competition in various industries. However, how to train statistics talents in the new era has naturally become the focus of teaching, and the traditional statistical teaching model is also facing great reform.
\end{abstract}

\section{Disadvantages of Traditional Statistics}

The Teaching Content does not Apply to Big Data's Time. Statistics, as a discipline to understand the total quantitative characteristics of objective phenomena and the relationship between quantity and quantity, has a relatively long history of development, and the statistical methods have mostly been perfected and summarized by many predecessors, so the contents of statistics are relatively unified. Teaching methods are also relatively fixed[1].In the past two decades, statistics courses for major economic management majors in major universities and colleges have generally been "applied statistics", "principles of statistics", "market investigation and prediction" and so on. However, many of the contents in these courses can no longer adapt to big data's time. Even out of touch with it. For example, its traditional statistical methods of collecting data are mainly sample surveys, then data collation, data classification. After that, not only do related descriptive statistical analysis, but also do extrapolation statistical analysis, there are many steps. The calculation is complicated. For big data, he abandoned the sampling survey of statistics and used the general method of sample data survey to infer the correlation rather than causality of things. From this point of view, the traditional statistical thinking and big data's computational thinking are quite different. But many teachers also ignore this point, resulting in students can not understand and accept new thinking and new ideas, can not understand the characteristics of the two, only one-sided study of the methods of statistics, hindered the expansion of ideas[2].

Teaching Methods are Limited. For the current statistical courses, teachers usually use case analysis and classroom teaching methods. For theoretical knowledge, teachers generally use the combination of teaching and statistical cases to explain. For the practical application chapters, such as investigation and statistics, data collation, data analysis and so on, the teaching methods such as social sampling survey and computer analysis are often used to express the relationship between the data. In addition, teachers often use basic data processing software to teach students to use computer tools to analyze data. However, although the above measures also seem reasonable, in 
fact, there are greater limitations. Big data's first feature is that he has a large amount of data, and has a variety of structures. Ordinary data analysis software, such as EXCEL he SPSS, is simply unable to meet big data's calculations. Therefore, there is a technical lag in the equipment configuration of statistics teaching. Teachers should teach advanced technical software such as SAS,R, combined with big data's characteristics, and strive to popularize big data's treatment and analysis methods for every student[3].

The Practice Teaching is Insufficient. Statistics is a methodology of scientific creation, in its long development process cannot do without innovation and idea. In such a background, modern statistics basically rely on mathematical knowledge to support, but at the same time to know, to serve the practice of statistics is derived, its significance is not restricted to formulas, methods of teaching, but also includes the research and prediction of actual events, in order to guide the practical work with the data and theory. In the practical teaching process, teachers tend to be statistical principle, concept and statistical methods to describe the good detail, but ignore the practice teaching knowledge to practical therefore, lead the students to understand the course of deviation, that is essentially mathematical statistics, as long as the master, master formula, do enough exercises will be able to learn this subject. This kind of deviation to know From the teachers put more emphasis on the teaching of theoretical knowledge, and dilute the practical teaching[4]. The big data is on the contrary, relatively speaking, big data is just emerging in recent years, the theory of knowledge was not so perfect and mature, but in practical application it is no less, than the statistics, master the data have higher requirements for the practice of modern statistics. For the talents, firmly grasp the relevant theoretical knowledge is necessary, and how the data and theoretical knowledge into practical work is the key challenge facing them. Therefore, teachers should combine big data, carry out rich and colorful development teaching activities, increase the proportion of practice teaching in the curriculum.

\section{The Influence of Big Data's Time on Statistics}

The rise and arrival of big data not only impact on the traditional statistical theory and teaching methods, but also make the statistical work face a new round of challenges and opportunities. For big data, its role and significance lies in statistical data, analysis of data, and service to society. This requires people engaged in statistics to be able to make use of relevant theoretical knowledge of statistics and combine the technical characteristics of big data. The development and use of vast amounts of data information for the service of society, and the current statistical teaching is out of line with the new era, therefore, the need for teaching staff in theory and methodology must be reformed, in this respect, Big data's time has produced the pressure and the threat to the statistics to a certain extent[5].

But at the same time, big data's time focused on cultivating talents' statistical thinking. Many classic statistical thinking, such as static thinking, variant thinking, dynamic thinking, hypothetical thinking, and so on, have become less suitable under the background of big data. Therefore, modern statistics should abandon some backward thinking methods and carry out a series of innovation and reform according to big data's characteristics of large amount of data and high degree of complexity in order to meet the needs of modern statistics. Therefore, the emergence of big data has indirectly promoted the development of statistics in the direction of more advanced and more modern, which will have a milestone significance in the history of statistics development.

\section{Reform of Statistics Teaching}

Change the Teaching Thought. Under the background of big data, the statistical method is far from satisfied with the large amount of data, the complexity of data types, the advanced data processing and so on. Therefore, in statistics teaching, teachers should first change the inherent mode of thinking, create new teaching ideas, and promote teaching reform. First of all, we should understand the difference between big data and statistics in theory and data: in data aspect, the sample of statistics comes from the limited sample data of sample survey, while the data of big data 
is all data, and its data range is more extensive and diverse; For the study subjects, statistics is often a technical means, formula method as the center, while big data has a data research center, for research ideas, statistics is based on the causal relationship between the data. Big data is based on the correlation between the data. Therefore, in view of these differences, teachers should take corresponding reform measures[6].

In classroom teaching, teachers should appropriately reduce the proportion of explaining formula principles, and lay stress on training students' data collation, data analysis ability training, and strengthening the understanding and understanding of big data.

Change the way of teaching. In explaining the causality thinking in statistics, we interspersed some relevant relationship ideas that accord with big data's characteristics, and reflected certain laws with the data itself as the center, so that students could not lose the core ideas and methods of statistics. Can also master big data's data thinking mode.

Practice reasonably. Teachers should pay attention to combining statistics with big data's method when assigning homework to students. How to design a problem with statistics and big data so that students can get comprehensive and systematic training and improve their comprehensive knowledge literacy.

Pay attention to practice. After teaching students the necessary EXCEL data analysis methods, teachers can introduce some software used by big data, such as SPSSs, so that students can keep up with the times and understand new technologies.

Strengthen Practical Teaching. As mentioned above, statistics, as a mathematical-based discipline, is often inseparable from the teaching of theoretical knowledge. In the actual teaching, many teachers only talk about the theory of knowledge, clear and vivid, but the use of statistics in practice is a sentence, do not pay attention to. Therefore, practical teaching is often the weakest link in statistics courses. In the context of big data, whether or not the theoretical data more valued by relevant enterprises can guide the actual work, theory has been played down to a certain extent. Objectively speaking, the theory should serve the reality. If it can not be applied to the reality, then the theory will become pale and meaningless. Therefore, it is both necessary and necessary to reduce theoretical knowledge and strengthen practical teaching.

The derivation of complicated statistical formula and the concept can not be studied too much, and the principle and design method can be described. For example, we can carry out rich and varied teaching activities to make students feel the charm of data and make students attach importance to the practical application of statistics.

The model-driven teaching model is transformed into the data-driven teaching model. The practical teaching system of case teaching, experimental teaching and extracurricular practice is established, and the statistical theory is combined with the statistical software. The new technology of data filtering and data mining is introduced in practical teaching.

Optimizing the Content and Structure of the Course. The theory and mode of thinking of big data era had a great impact on statistics. Many of the contents of statistics are obviously different from big data, and many of them are not fully applicable to the modern production model. Therefore, it is necessary to change the content of teaching curriculum properly, optimize the theoretical structure and transfer new concepts. But this does not mean that we should abandon and completely deny the original theoretical system, and we should critically inherit the new ideas under big data, and for statistics, it has been able to develop for hundreds of years. Up to now, all aspects of our life have to use the thought of statistics, so although it has something worth carrying forward and positive, we can not completely deny the thought of statistics because of the emergence of big data. We should follow the trend of the times, reform the content of books, optimize the structure of the curriculum, remove the inapplicable and obsolete thinking patterns, and preserve useful ideas and methods, on the other hand, It is necessary to combine big data's theoretical characteristics with the thinking mode of statistics in order to create a curriculum suitable for modernization. On the one hand, we should make every effort to cultivate the students' statistical thinking, on the other hand, we should be able to understand big data to a certain extent. Use big data, will not lag behind the times. For example, teachers can use classroom discussions to enable students to express their views 
on big data's thoughts and statistical thoughts. On the other hand, teachers should appropriately add relevant big data materials to the courseware. In addition to reducing the number of useless chapters, teachers can find multimedia resources about big data and enrich the content of the course.

Develop Vocational Skills and Practical Abilities. In the final analysis, the 21st century is a necessary talent, and the talent becomes a talent, is able to serve the society. Statistics is a course closely related to social and economic practice, which is widely used in economic management in real life. Therefore, it is very important for teachers to cultivate professional ability, which not only makes statisticians have the opportunity to display their talents, but also reflects the social value of statistics itself. In order to cultivate students' vocational skills, we must first strengthen the cultivation of statistical thinking, because statistical thinking, such as average thought, variation thought, static thought and so on, are all effective ways to strengthen the analysis and processing of data. Secondly, it is necessary to popularize the relevant professional knowledge to the students in order to make the students not unable to use the knowledge of statistics and adapt to the information mode of big data era. At the same time, teachers should pay attention to the practical and applied ability of students, not only to train application-oriented talents, but also to train composite talents, so that students can not only be able to use their studies for practical purposes, but also have the ability of self-study, independent thinking and scientific research. Can really adapt to the arrival of big data era.

\section{Conclusion}

It is undeniable that big data's arrival did impact the mathematical-based discipline of statistics. But from a positive point of view, big data's challenge to statistics has also contributed to the further development of statistics. Because after hundreds of years of development and perfection, the system of statistics has been relatively fixed, and big data forced statistics to make reforms, and its teaching system will be more advanced and more modern, so it has certain positive significance. For statistics and big data, we should objectively evaluate, critically absorb both advantages and disadvantages. For teachers, how to combine big data's characteristics in statistics, there is still a lot of reform way to go, teachers still need more thinking and efforts.

\section{References}

[1] HE Lihong, Thinking and Practice on Teaching Reform of Statistics Course in Management Specialty, Higher Education of Sciences,2014,2.

[2] WU Xingguo, XIAO Lu, Training of Statistical Practice Ability of Higher Vocational Students Based on Market Demand, Modern Enterprise Education,2014,1.

[3] SONG Xiaoqing, My opinion on the Teaching Reform of Statistics in Higher Vocational Colleges. Market Conditions,2012,1.

[4] ZHU Huaiqing. The Influence of Big Data's Time on the Teaching of Undergraduate Economics and Management Statistics. Journal of Higher Education,2014,9.

[5] XUE Yan. Reform of Teaching System of Statistics Specialty in Big Data Era. Education Teaching Forum.2015.

[6] Alvin Toffler,. HUANG Mingjian, The third wave[M], Citic Press Corp.,2006. 